\title{
Impacto do algodoeiro Bt na dinâmica populacional do pulgão-do-algodoeiro em casa de vegetação
}

\author{
Edison Ryoiti Sujii( ${ }^{(1)}$, Pedro Henrique Brun Togni(2), Erich Yukio Tempel Nakasu(1), Carmen Silvia Soares Pires ${ }^{(1)}$, \\ Débora Pires de Paula ${ }^{(1)}$ e Eliana Maria Gouveia Fontes ${ }^{(1)}$ \\ (1)Embrapa Recursos Genéticos e Biotecnologia, Caixa Postal 01372, CEP 70849-970 Brasília, DF. E-mail: sujii@cenargen.embrapa.br, \\ erichnakasu@cenargen.embrapa.br, cpires@cenargen.embrapa.br, debora@cenargen.embrapa.br, eliana@cenargen.embrapa.br \\ (2)Universidade de Brasília, Campus Darcy Ribeiro, Caixa Postal 04457, CEP 70919-970 Brasília, DF. E-mail: pedrohbtogni@yahoo.com.br
}

\begin{abstract}
Resumo - O objetivo deste trabalho foi desenvolver um protocolo experimental para avaliar o impacto do algodoeiro $\mathrm{Bt}$ na bionomia e na escolha de plantas para colonização pelo pulgão-do-algodoeiro (Aphis gossypii). A bionomia do pulgão foi avaliada em casa de vegetação com insetos criados em gaiolas individuais com plantas de algodão Bt, da variedade DP 404 BG (Bollgard), ou sua isolinha não transformada DP 4049. Gaiolas contendo vasos com plantas de algodoeiro Bt e não-Bt foram usadas como arena de escolha, para a avaliação de preferência de adultos alados. O período pré-reprodutivo e reprodutivo, a longevidade, a curva de sobrevivência, a produção de prole total e diária por fêmea e a curva acumulada de produção de prole da população não apresentaram diferenças significativas. Não foi observada diferença na escolha de plantas para colonização por indivíduos alados, o que indica taxas equivalentes de colonização nas populações iniciais. $\mathrm{O}$ algodoeiro Bt não afeta a dinâmica populacional de A. gossypii e não aumenta seu potencial de risco como praga.
\end{abstract}

Termos para indexação: Aphis gossypii, biossegurança, organismo geneticamente modificado, praga não-alvo, toxina Cry.

\section{Impact of Bt cotton on the population dynamics of the cotton aphid in greenhouse}

\begin{abstract}
The objective of this work was to develop an experimental protocol to assess the impact of Bt cotton on bionomics and on plant choice for Aphis gossypii colonization. The bionomics of the cotton aphid was assessed in greenhouse with insects reared in individual cages containing Bt cotton plants of the variety DP 404 BG (Bollgard) or its nontransformed isoline DP 4049. Cages with Bt cotton and non-Bt cotton were used as choosing arena for evaluation of winged adults preference. There was no significant difference for pre-reproduction period (immature phase), reproduction period, longevity, survivorship curve total and daily production of offspring by female, and curve of accumulated production of offspring by the population. There was no preference of colonization for any plant by winged adults, which indicates equivalent rates of colonization of the initial populations. Bt cotton plants do not affect the population dynamics of $A$. gossypii, and do not increase its potential risk as pest.
\end{abstract}

Index terms: Aphis gossypii, biosafety, genetic modified organism, nontarget pest, Cry toxin.

\section{Introdução}

O pulgão-do-algodoeiro - Aphis gossypii Glover (Hemiptera: Aphididae) - é uma das principais pragas do algodoeiro em razão dos danos diretos, causados pela sucção do floema, e indiretos pela transmissão de viroses. Além disso, uma substância açucarada ("honeydew"), exsudada pelo pulgão, favorece a ocorrência de fungos (fumagina) que prejudicam a qualidade das fibras do algodoeiro na fase final de seu ciclo (Fontes et al., 2006).
Essa praga coloniza o algodoeiro desde a fase de plântula e se reproduz de forma rápida e abundante por partenogênese telítoca e seu desenvolvimento, sobrevivência e fecundidade são afetados por fatores externos, como temperatura e alimentação (Xia et al., 1999; Liu et al., 2005). Essas características permitem que o afídeo produza várias gerações e altas densidades populacionais a cada safra, o que favorece a rápida seleção de indivíduos resistentes a fatores do ambiente restritivos ao seu crescimento populacional (Liu et al., 2005). 
O controle de lagartas pela toxina Cry, produzida pelo algodoeiro Bt, é apropriado para o programa de manejo das pragas do algodoeiro, por possibilitar a redução do número de aplicações de inseticidas químico-sintéticos e por promover controle mais efetivo contra diversas espécies de lagartas (Fitt \& Wilson, 2000; Sharma \& Ortiz, 2000). No entanto, apresenta o risco potencial de facilitar indiretamente aumento de populações do pulgão. Diferentes estudos têm avaliado o efeito do algodão Bt sobre a abundância de pulgões e outros hemípteros e apresentam resultados contrastantes. Estudos de campo conduzidos nos Estados Unidos (Sisterson et al., 2004), África do Sul (Vaissayre et al., 2005) e Austrália (Whitehouse et al., 2005) não mostraram diferenças na abundância de afídeos. Por sua vez, avaliações das populações de pulgões em campos de algodão $\mathrm{Bt}$ e não-Bt, na China, mostraram maior abundância de pulgões em parcelas de algodão $\mathrm{Bt}$ (Deng et al., 2003). Em trabalho realizado por $\mathrm{Wu}$ \& Guo (2003), nas mesmas condições, mas em outra região da China, não foram encontradas diferenças nas populações de pulgões. Mudanças das interações ecológicas no agroecossistema ou efeitos pleiotrópicos, causados pela transgenia, podem ter tornado essa praga não-alvo do algodoeiro Bt a mais importante da cultura e representa um fator de biossegurança a ser analisado (Sujii et al., 2006).

Adicionalmente, estudos em laboratório mostraram que pulgões alimentados por três gerações em algodoeiro Bt que expressa Cry1Ac e CpTI apresentaram maior capacidade reprodutiva e maiores taxas de sobrevivência em comparação com indivíduos alimentados em algodoeiro não-Bt, com possível impacto sobre a dinâmica populacional da espécie (Liu et al., 2005). Ao se alimentar do floema, o inseto provavelmente irá ingerira toxina $\mathrm{Bt}$, e essa toxina pode ter ação desconhecida sobre sua bionomia, além de passá-la a níveis tróficos superiores por meio da predação ou do parasitismo.

O objetivo deste trabalho foi desenvolver um protocolo experimental para avaliar o impacto do algodoeiro Bt na bionomia e na escolha de plantas para colonização pelo pulgão-do-algodoeiro.

\section{Material e Métodos}

O ciclo de vida e a reprodução do pulgão-do-algodoeiro foram avaliados em plantas de algodão $\mathrm{Bt}$ da variedade
DP 404 BG (Bollgard) e sua isolinha não transformada DP 4049. O experimento foi conduzido em casa de vegetação, a $25 \pm 4^{\circ} \mathrm{C}$, em delineamento inteiramente ao acaso, com 50 repetições. Cada parcela experimental foi constituída por uma gaiola de plástico com $32 \mathrm{~cm}$ de altura e $18 \mathrm{~cm}$ de diâmetro (capacidade de $6 \mathrm{~L}$ ) com um vaso de $10 \mathrm{~cm}$ de diâmetro e $7 \mathrm{~cm}$ de altura (capacidade de $0,45 \mathrm{~L}$ ). Na parte superior das gaiolas havia uma abertura recoberta com tela de nylon (voile), o que permitiu aeração do sistema.

Sementes de algodão $\mathrm{Bt}$ ou sua isolinha não-transformada foram plantadas nos vasos em solo esterilizado e adubado, com apenas uma plântula por vaso. As sementes foram doadas pela empresa Delta \& Pine. A rega foi provida por um sistema de gotejamento individual e a base da planta foi recoberta por uma placa de isopor para evitar a perda de indivíduos no solo e não prejudicar sua contagem. Três ninfas neonatas de pulgão (com menos de 24 horas de vida), provenientes de algodão não-Bt, foram colocadas em cada planta para garantir o estabelecimento de pelo menos uma. Quando as plantas apresentavam duas folhas verdadeiras estendidas e, após três dias, foi deixada apenas uma ninfa por planta. Os pulgões foram observados, diariamente, para determinar o tempo de desenvolvimento na fase imatura (período pré-reprodutivo), o período reprodutivo e a quantidade média e acumulada de prole de cada indivíduo, além da longevidade e da sobrevivência. As ninfas recém-emergidas, em cada gaiola, foram registradas e retiradas, diariamente, para determinar a fecundidade e o ritmo reprodutivo das fêmeas. As gaiolas em que as fêmeas não alcançaram a fase reprodutiva foram retiradas do experimento por não permitir avaliar a duração da fase imatura e da fase reprodutiva, além da quantidade média e acumulada de prole produzida por fêmea. As variáveis medidas foram comparadas pelo teste $t$ de Student.

A colonização de plantas de algodão, pela forma alada do pulgão $A$. gossypii, foi comparada em gaiolas de $30 \times 30 \mathrm{~cm}$ e $50 \mathrm{~cm}$ de altura, que serviam como arenas de escolha para a colonização pelos insetos de uma planta $\mathrm{Bt}$ ou uma planta não transformada. Cada gaiola formava uma replicação com dois vasos de $10 \mathrm{~cm}$ de diâmetro e $7 \mathrm{~cm}$ de altura (capacidade de 0,45 L), com uma planta com duas folhas verdadeiras expandidas. $\mathrm{O}$ experimento teve dez repetições e foi conduzido em casa de vegetação nas mesmas condições acima descritas. Grupos de dez pulgões alados foram liberados 
por gaiola em um frasco de plástico posicionado no centro da gaiola e deixado aberto para que os indivíduos tivessem chance de escolha. Os pulgões alados foram provenientes de colônia pré-estabelecida do Laboratório de Ecologia, Semioquímicos e Biossegurança do Núcleo Temático de Controle Biológico da Embrapa Recursos Genéticos e Biotecnologia, onde foram mantidos em plantas de Gossypium hirsutum L. sob luz artificial e em folhas dessa espécie em ágar. Depois de três dias as gaiolas foram abertas e o número de pulgões por planta foi contabilizado para determinar se $A$. gossypii possui algum padrão de preferência pelo algodão $\mathrm{Bt}$ ou não-Bt. As médias foram comparadas pelo teste $t$ com o auxílio do programa SigmaStat.

As amostras foliares para quantificação da proteína Cry1Ac por imunodetecção foram preparadas de acordo com Holt et al. (2002). O nível de expressão de Cry1Ac em $1 \mathrm{~g}$ de tecido foliar, recém-coletado e congelado em nitrogênio líquido, foi estimado pela técnica de ELISA indireta (Enzyme-Linked Immuno-Sorbent Assay) utilizando-se anticorpos monoclonais contra-Cry1Ac e anticorpos secundários conjugados à peroxidase, revelados com substrato cromogênico Tetrametil benzidina (TMB). Os anticorpos monoclonais foram produzidos pelo Laboratório Célula B da Universidade Federal do Rio Grande do Sul. Dez unidades experimentais foram utilizadas, sendo cada estimativa realizada em triplicata. Para a construção da curva de calibração, foram utilizados padrões de proteína Cry1Ac pura nas concentrações de 15,6,31,2, 62,5, 125, 250, 500 e $1.000 \mathrm{ng} \mathrm{mL}^{-1}$. A proteína Cry1Ac pura foi importada da Case Western Reserve University SOM, Department of Biochemistry, Cleveland - OH/USA. As reações foram paradas com ácido sulfúrico $1 \mathrm{~N}$ antes da leitura da absorbância a $450 \mathrm{~nm}$, em espectrofotômetro BenchMark Plus Microplate (Bio-Rad).

\section{Resultados e Discussão}

Apenas 5\% dos insetos não alcançaram a fase adulta - dois em plantas Bt e três em plantas não-Bt. As plantas amostradas $(n=10)$ em casa de vegetação expressaram, em média, $0,51 \pm 0,08 \mu \mathrm{g}$ de toxina Cry 1 Ac por grama de tecido foliar fresco, de acordo com estimativas obtidas pelo teste de ELISA. As folhas não apresentaram sintomas visíveis de danos, como enrolamento e clorose, causados pela alimentação contínua dos pulgões durante o experimento, o que permitiu que os possíveis efeitos da toxina, sobre a bionomia do pulgão, fossem avaliados sem interferência dos próprios insetos na qualidade nutricional do alimento.

Os pulgões apresentaram taxas de sobrevivência elevadas (95\%) nas gaiolas, e apenas 3\% dos insetos não alcançaram a fase reprodutiva - dois em planta $\mathrm{Bt}$ e um em planta não-Bt -, além de fecundidade em torno de 47 ninfas por fêmea. Esse dado equivale ao melhor desempenho reprodutivo obtido em outros experimentos com a mesma espécie após três gerações (Liu et al., 2005). As varáveis biológicas avaliadas apresentaram boa padronização com coeficiente de variação inferior a $45 \%$ e permitiram o uso de testes paramétricos.

As plantas de algodoeiro Bt não afetaram o desenvolvimento das ninfas e a fecundidade do pulgão em todas as variáveis testadas (Tabela 1).

As curvas de sobrevivência das populações criadas em algodoeiro $\mathrm{Bt}$ e não-Bt apresentaram o mesmo padrão com aumento da mortalidade a partir de 16 dias de vida e longevidade máxima em torno de 38 dias (Figura 1). A curva de sobrevivência do tipo I, atípica para insetos (Begon et al., 1996), pode ser explicada pela exclusão de predadores e parasitóides no experimento e pela ausência de outros possíveis fatores de mortalidade como a interação inseto-planta.

A taxa reprodutiva líquida da população, expressa pela produção média de prole total por fêmea, não diferiu significativamente nas fêmeas criadas na planta geneticamente modificada, em relação às plantas não-Bt (Tabela 1). Da mesma forma, a taxa intrínseca de aumento populacional diário (Begon et al., 1996) foi de $r_{m}=0,3711$, para a planta geneticamente modificada, bastante semelhante àquela observada para o controle, $r_{\mathrm{m}}=0,3841$. Liu et al. (2005) verificaram um padrão similar na China onde indivíduos de A. gossypii

Tabela 1. Bionomia (média \pm desvio-padrão) do pulgão-do-algodoeiro (Aphis gossypii) em algodão Bt (DP 404 BG) e sua isolinha não transformada (DP 4049) em casa de vegetação $\left(25 \pm 4^{\circ} \mathrm{C}\right)$.

\begin{tabular}{lcccc}
\hline Algodão & Período pré-reprodutivo (dias) & Período reprodutivo (dias) & Longevidade (dias) & Prole total por fêmea \\
\hline DP 404 BG & $7,25 \pm 1,45$ & $16,35 \pm 5,91$ & $20,47 \pm 6,56$ & $47,26 \pm 19,20$ \\
DP 4049 & $7,12 \pm 1,24$ & $16,18 \pm 6,66$ & $20,98 \pm 7,29$ & $46,98 \pm 21,31$ \\
\hline
\end{tabular}


mantidos em algodão $\mathrm{Bt}$ apresentaram $\mathrm{r}_{\mathrm{m}}=0,326$ e $r_{m}=0,391 \mathrm{em}$ plantas não-Bt, durante a primeira geração. Mesmo após três gerações, os valores de $r_{m}$ mantiveram-se semelhantes, o que confirma o padrão apresentado na primeira geração desses afídeos.

As curvas de produção média diária de ninfas por fêmea em algodoeiro Bt e não-Bt (Figura 2) e de produção acumulada de ninfas por fêmea em algodoeiro Bt e não-Bt (Figura 3) não apresentaram diferenças significativas. A curva de fecundidade média das fêmeas iniciou em torno de 6 dias, com pico de fecundidade entre 12 e 14 dias, e redução gradativa até os 34 dias. A ausência de alterações bruscas na dinâmica de produção de prole confirma que fatores de estresse como oscilações bruscas na qualidade nutricional do alimento não ocorreram durante o experimento.

Apesar de este trabalho ter sido conduzido em casa de vegetação, a $25 \pm 4^{\circ} \mathrm{C}$, o ciclo de vida - considerando-se a fase imatura, período reprodutivo e longevidade

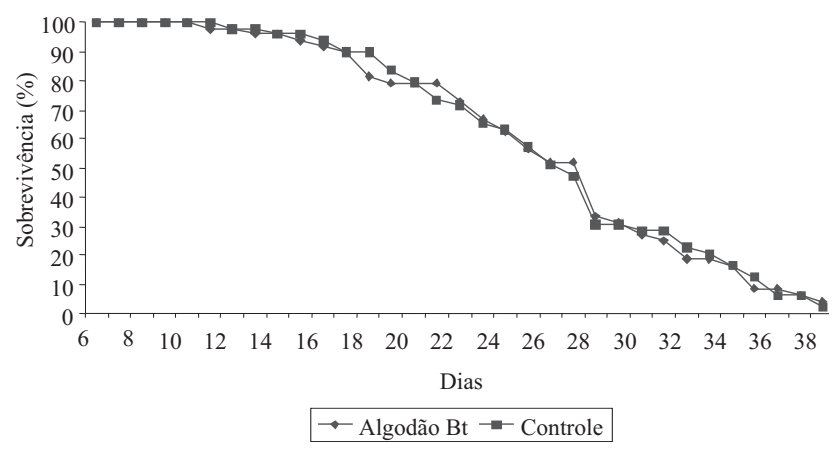

Figura 1. Curva de sobrevivência da população do pulgão-do-algodoeiro (Aphis gossypii) criada em algodoeiro Bt (DP 404 BG) e não-Bt (DP 4049), em casa de vegetação $\left(25+4^{\circ} \mathrm{C}\right)$.

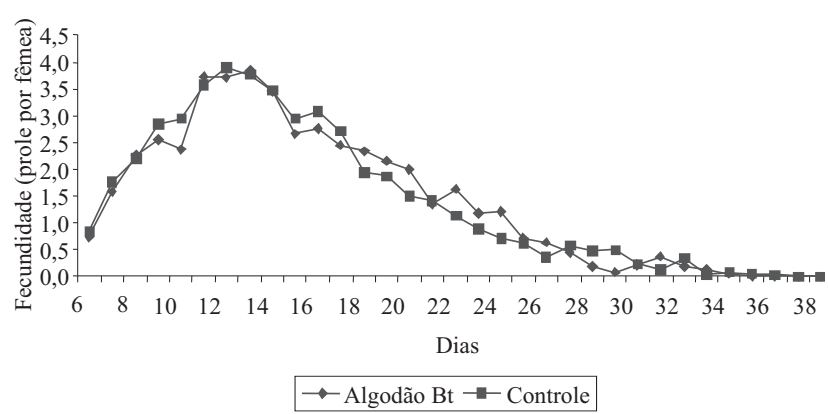

Figura 2. Fecundidade média diária do pulgão-do-algodoeiro (Aphis gossypii), criado em algodoeiro Bt (DP 404 BG) e não-Bt (DP 4049), em casa de vegetação $\left(25 \pm 4^{\circ} \mathrm{C}\right)$. total - de A. gossypii apresentou média e amplitude de variação semelhante aos resultados apresentados em outros trabalhos conduzidos em câmaras climatizadas com menor amplitude de variação (Vendramin \& Nakano, 1981; Xia et al., 1999; Micheloto \& Busoli, 2003; Liu et al., 2005). A taxa de sobrevivência em ambos os tratamentos foi elevada (acima de 98\%). Essa taxa e a fecundidade média de aproximadamente 47 ninfas por fêmea, além do ritmo de produção de prole pelo conjunto de fêmeas medido pela fecundidade média diária e fecundidade acumulada (Figuras 2 e 3), são similares aos resultados obtidos por Liu et al. (2005) e Vendramin \& Nakano (1981) e ligeiramente menores que os resultados de Micheloto $\&$ Busoli (2003), que obtiveram fecundidade média de $5,7 \pm 0,26$ ninfas por dia, para um período reprodutivo médio de $15,5 \pm 0,93$ dias em câmaras climatizadas. Esses dados indicam a qualidade do protocolo proposto para a realização de bioensaios com $A$. gossypii.

$\mathrm{O}$ número de pulgões alados em algodoeiro $\mathrm{Bt}=1,08 \pm 0,39$ e não- $\mathrm{Bt}=1,53 \pm 0,44$, assim como $\mathrm{o}$ número total (alados e ninfas) em algodoeiro $\mathrm{Bt}=7,92 \pm 2,78$ e não-Bt $=8,63 \pm 2,49$, observados nas arenas de preferência, aos três dias após a liberação dos alados, não diferiu significativamente, o que permite inferir que o algodoeiro Bt não interferiu nas taxas de estabelecimento dos adultos alados de $A$. gossypii e na formação inicial das colônias.

Todas as variáveis testadas confirmam a biossegurança do evento DP 404 Bollgard, em relação aos efeitos da toxina Cry1 Ac, na bionomia do pulgão-do-algodoeiro, uma espécie-praga não-alvo da tecnologia. A inserção de um gene exógeno, que poderia ocasionar efeitos epistáticos ou pleiotrópicos sobre os nativos e que altera

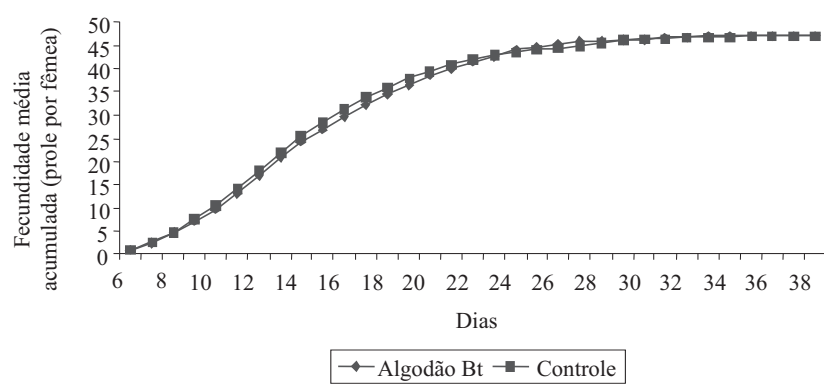

Figura 3. Fecundidade acumulada diária do pulgão-doalgodoeiro (Aphis gossypii), criado em algodoeiro $\mathrm{Bt}$ (DP 404 BG) e não-Bt (DP 4049), em casa de vegetação $\left(25+4^{\circ} \mathrm{C}\right)$. 
o fenótipo vegetal hospedeiro, não afetou os parâmetros que poderiam alterar a capacidade de crescimento intrínseco das populações de pulgão (Sujii et al., 2006). Além disso, foi observado em trabalhos de campo que o algodão $\mathrm{Bt}$ pode preservar maior densidade de predadores e menor densidade de $A$. gossypii, quando comparado a parcelas com aplicação de inseticidas para o controle de lepidópteros (Wu \& Guo, 2003). Isso demonstra a alta especificidade dessa tecnologia para o controle de organismos-alvo, sem causar efeitos positivos ou negativos em populações não-alvo, como as do pulgão-do-algodoeiro. Entretanto, os padrões observados podem variar de acordo com a região.

Este trabalho comprova a biossegurança do algodoeiro Bt (DP 404 BG Bollgard) em relação ao pulgão $A$. gossypii, em razão da não detecção de impacto significativo em sua dinâmica populacional. No entanto, outros fatores como efeito da toxina em inimigos naturais ou o uso correto de inseticidas devem ser aprofundados caso ocorram surtos populacionais do pulgão-do-algodoeiro em plantios comerciais, como já observado em outros países (Deng et al., 2003). Além disso, o protocolo utilizado pode ser aplicado a outros insetos sugadores não-alvo em estudos de biossegurança de plantas Bt e para estudos com interações em outros níveis tróficos como para predadores e parasitóides.

\section{Conclusões}

1. O algodoeiro $\mathrm{Bt}$, que expressa a proteína Cry $1 \mathrm{Ac}$, não apresenta ação deletéria ou favorece positivamente alterações no ciclo de vida, sobrevivência, fecundidade e formação de colônias do pulgão Aphis gossypii, em condições de casa de vegetação.

2. O protocolo desenvolvido é eficiente para a avaliação do efeito de algodoeiros transgênicos que expressam a toxina $\mathrm{Bt}$, em insetos sugadores não-alvo, como Aphis gossypii.

\section{Agradecimentos}

Ao Conselho Nacional de Desenvolvimento Científico e Tecnológico, pelas bolsas de pesquisa e iniciação científica; à Financiadora de Estudos e Projetos, pelo apoio financeiro; a Kelly Cavalcante, Viviane Beserra, Paulo dos Santos e Thiara Bernardes, pelo auxílio na montagem dos experimentos e na coleta dos dados; ao David Andow, pelas sugestões e críticas ao trabalho.

\section{Referências}

BEGON, M.; HARPER, J.L.; TOWNSEND, C.R. Ecology: individuals, populations and communities. $3^{\text {th }}$ ed. Oxford: Blackwell Science, 1996. 1068p.

DENG, S.D.; XU, J.; ZHANG, Q.W.; ZHOU, S.W.; XU.; G.J. Effect of transgenic Bacillus thuringiensis cotton on population dynamics of non-target pests and natural enemies. Acta Entomologica Sinica, v.46, p.1-5, 2003.

FITT, G.P.; WILSON, L.J. Genetic engineering in IPM: Bt cotton. In: KENNEDY, G.G.; SUTTON, T.B. (Ed.). Emerging technologies for integrated pest management. St. Paul: APS Press, 2000. p.108-125.

FONTES, E.M.G.; RAMALHO, F. de S.; UNDERWOOD, E.; BARROSO, P.A.V.; SIMON, M.F.; SUJII, E.R.; PIRES, C.S.S.; BELTRÃO, N.; LUCENA, W.A.; FREIRE E.C. The cotton agricultural context in Brazil. In: HILBECK, A.; ANDOW, D.A.; FONTES, E.M.G. (Ed.). Environmental risk assessment of genetically modified organisms: methodologies for assessing Bt cotton in Brazil. Wallingford: CABI Publishing, 2006. v.2. p.21-66.

HOLT, H.E.; MARES, C.; AKHURST, R. Determination of the cry protein content of $\mathrm{Bt}$ transgenic cotton. Canberra: CSIRO, 2002. 18p. (CSIRO Entomology. Technical Report, 92).

LIU, X.D.; ZHAI, B.P.; ZHANG, X.X.; ZONG, J.M. Impact of transgenic cotton plants on a non-target pest, Aphis gossypii Glover. Ecological Entomology, v.30, p.307-315, 2005.

MICHELOTO, M.D.; BUSOLI, A.C. Aspectos biológicos de Aphis gossypii Glover 1877 (Hemiptera: Aphididae) em três cultivares de algodoeiro e em três espécies de plantas daninhas. Ciência Rural, v.33, p.99-1004, 2003.

SHARMA, H.C.; ORTIZ, R. Transgenics, pest management, and the environment. Current Science, v.79, p.421-437, 2000.

SISTERSON, M.S.; BIGGS, R.W.; OLSON, C.; CARRIÈRE, Y.; DENNEHY, T.J.; TABASHNIK, B.E. Arthropod abundance and diversity in $\mathrm{Bt}$ and non-Bt cotton fields. Environmental Entomology, v.33, p.921-929, 2004.

SUJII, E.R.; LÖVEI, G.L.; SÉTAMOU, M.; SILVIE, P.; FERNANDES, M.G.; DUBOIS, G.S.J.; ALMEIDA, R.P. Non-target and biodiversity impacts on non-target herbivorous pests. In: HILBECK, A.; ANDOW, D.A.; FONTES, E.M.G. (Ed.). Environmental risk assessment of genetically modified organisms. Wallingford: CABI Publishing, 2006. v.2. p.133-154.

VAISSAYRE, M.; HOFS, J.; SCHOEMAN, A.; MELLET, M. Impact des cotonniers génétiquement modifiés sur la biodiversité de la faune entomologique: le cas du coton Bt en Afrique du Sud. International Journal of Tropical Insect Science, v.25, p.63-72, 2005.

VENDRAMIN, J.D.; NAKANO, O. Aspectos biológicos de Aphis gossypii Glover 1877 (Homoptera: Aphididae) em algodoeiro. Anais da Sociedade Entomológica do Brasil, v.10, p.163-173, 1981.

WHITEHOUSE, M.E.A.; WILSON, L.J.; FITT, G.P. A comparison of arthropod communities in transgenic $B t$ and conventional cotton in Australia. Environmental Entomology, v.34, p.1224-1241, 2005. 
WU, K.; GUO, Y. Influences of Bacillus thuringiensis Berliner cotton planting on population dynamics of the cotton aphid, Aphis gossypii Glover, in Northern China. Environmental Entomology, v.32, p.312-318, 2003.
XIA, J.Y.; VAN DER WERF, W.; RABBINGE, R. Influence of temperature on bionomics of cotton aphid, Aphis gossypii, on cotton. Entomologia Experimentalis et Applicata, v.90, p.25-35, 1999.

$\overline{\text { Recebido em } 4 \text { de maio de } 2008 \text { e aprovado em } 22 \text { de setembro de } 2008}$ 